\title{
First Principles Modeling of the Temperature Dependent Ternary Phase Diagram for the Cu-Pd-S System
}

\author{
William Paul Huhn ${ }^{\mathrm{a}, *}$, Michael Widom ${ }^{\mathrm{a}}$, Michael C. Gao ${ }^{\mathrm{b}, \mathrm{c}}$ \\ ${ }^{a}$ Department of Physics, Carnegie Mellon University, Pittsburgh, PA 15213, USA \\ ${ }^{b}$ National Energy Technology Laboratory, Albany, OR 97321, USA \\ ${ }^{c}$ URS Corporation, Albany, OR 97321, USA
}

\begin{abstract}
As an aid to the development of hydrogen separation membranes, we predict the temperature dependent phase diagrams using first principles calculations combined with thermodynamic principles. Our method models the phase diagram without empirical fitting parameters. By applying thermodynamic principles and solid solution models, temperature-dependent features of the Cu-Pd-S system can be explained, specifically solubility ranges for substitutions in select crystalline phases. Electronic densities of states calculations explain the relative favorability of certain chemical substitutions. In addition, we calculate sulfidization thresholds for the $\mathrm{Pd}-\mathrm{S}_{2}$ system and activities for the $\mathrm{Cu}-\mathrm{Pd}$ binary in temperature regimes where the phase diagram contains multiple solid phases.
\end{abstract}

\section{Introduction}

Sulfidization impedes the use of palladium-based membranes for hydrogen sequester and capture. Due to the presence of hydrogen sulfide $\left(\mathrm{H}_{2} \mathrm{~S}\right)$ in any practical feed gas, sulfur rapidly covers the surface of the membrane, rendering its catalytic properties inert. Pure palladium membranes have limited ap-

\footnotetext{
${ }^{*}$ Corresponding author

Email addresses: wph@andrew.cmu.edu (William Paul Huhn), widom@andrew.cmu.edu (Michael Widom)
}

Preprint submitted to Elsevier

May 19, 2018 
plication for hydrogen sequester and capture due to irreversible formation of bulk sulfides [1] and embrittlement due to lattice distortion caused by hydrogen atoms [2] diffusing through the bulk. Alloying palladium with other metals, such as silver [3] or gold [1], fixes many of the problems associated with palladium membranes, but these materials still suffer from sulfidization and are expensive. In the 2000s it was discovered that alloying palladium with copper [4, 5] dramatically reduces the rate of sulfidization and further decreases the price of these membranes, though still not eliminating sulfidization. In order to realize hydrogen capture and sequester on an industrial scale, new membranes with different chemical compositions that resist sulfidization need to be devised, and their reactivity to sulfur needs to be examined. Computational methods offer an attractive way to rapidly prototype different chemical families.

In this paper we computationally model the temperature-dependent phase diagram for the $\mathrm{Cu}-\mathrm{Pd}-\mathrm{S}$ system using first principles methods. Prior experimental work [6] determined the ternary phase diagram for the Cu-Pd-S system. We seek a simple and semi-quantitative model to gain insight into the essential features of the system, in contrast to complicated models with many fitting parameters that can yield close agreement with experiment at the cost of obscuring the underlying physics.

First, we describe our method for calculating ternary phase diagrams and apply it to $\mathrm{Cu}-\mathrm{Pd}-\mathrm{S}$. Our model begins with first principles total energies, moves to focus on substitutional entropy, then examines vibrations. Comparison with experimental results shows general agreement. Certain details of energetics are explored through examination of the electronic density of states. We then apply our model to predict sulfidization thresholds for Pd interacting with $\mathrm{S}$ dimers and activities in $\mathrm{Cu}-\mathrm{Pd}$ binaries.

\section{Methods and Calculations}

In order to calculate a phase diagram using first principles methods, all plausible crystal structures must be considered, in principle. In the case of $\mathrm{Cu}$ Pd-S, a wealth of experimental crystallographic data gives an excellent starting 
point, especially for the binary compounds. We generalize these binaries to ternary structures formed from substitutions of the ternary species into either lattice sites or interstitial sites. Once the $\mathrm{T}=0 \mathrm{~K}$ total energies for all likely crystalline structures have been calculated, it is straightforward to generate a $\mathrm{T}=0 \mathrm{~K}$ phase diagram by creating the convex hull of total energies.

Subramanian and Laughlin [7] determined the phase diagram for $\mathrm{Cu}-\mathrm{Pd}$ experimentally, and Li et al. created a CALPHAD model [8]. Above T=871K, the entire composition range of solid $\mathrm{Cu}-\mathrm{Pd}$ exists in fcc solid solution. Below this temperature other solid phases are present. $\beta$-CuPd has a $\mathrm{CsCl}$ structure and exhibits a $\mathrm{Cu}$-rich composition range extending to a composition of $58 \%$ $\mathrm{Cu}$. Trimarchi and Zunger [9] showed using an evolutionary algorithm that first principles calculations predict $\mathrm{cP} 2$ to be the expected ground state at equiatomic composition. At copper concentrations near 75\%, phases based on 1D and 2D long period superstructures (LPS) compete. Studies using ab initio methods to examine this region of the phase diagram have already been performed [10, 11]. As we are primarily concerned with the palladium-rich side of the phase diagram, we only calculate the ideal 1D LPS, $\mathrm{Cu}_{3} \mathrm{Pd}$.tP28, (using a notation of [chemical formula].Pearson symbol) and ignore the 2D LPS and phase solubility ranges in the 1D LPS.

Determination of the phase diagram for $\mathrm{Cu}-\mathrm{S}$ [12] using first principles calculations is problematic, as it contains an abundance of phases, many of which are non-stoichiometric or have large unit cells. We include only $\mathrm{Cu}-\mathrm{S}$ structures with well-defined crystallographic refinements, as we do not expect this discrepancy to affect our results on the palladium-rich side of the phase diagram. The Pd-S phase diagram [13] is relatively simple, containing $\mathrm{Pd}_{16} \mathrm{~S}_{7}, \mathrm{Pd}_{4} \mathrm{~S}, \mathrm{PdS}$, and $\mathrm{PdS}_{2}$ phases as line compounds at low temperature, with $\mathrm{Pd}_{3} \mathrm{~S}$ stabilized at $\mathrm{T}=829 \mathrm{~K}$. We summarize the phase diagrams here only for comparison; our method does not require pre-existing knowledge of the phase diagrams.

In order to add temperature dependence to the phase diagrams, we introduce free energy models for select phases of interest, all of which are based on substitutional solid solution models with sublattice filling (where for some 
structures, the "sublattice" is the entire lattice). When calculating the ternary phase diagram and the activities, we work in the Gibbs ensemble, where we specify temperature, pressure, and chemical concentration. We neglect pressure dependence in the solid phases' free energies, as solid compressibilities are low. Phonon free energies are included, in the harmonic approximation, giving free energies of form

$$
G_{t o t}=G_{\text {config }}+G_{\text {phonon }} .
$$

Electronic free energy differences between competing phases of interest $\left(\mathrm{Pd}_{16} \mathrm{~S}_{7}\right.$ versus $\mathrm{Pd}_{4} \mathrm{~S}$ and well-ordered fcc-CuPd versus $\beta$-CuPd at $50 \% \mathrm{Cu}$ ), were found to be less than $1.5 \mathrm{meV}$ /atom at temperatures as high as $1000 \mathrm{~K}$. These differences are within the margin of error expected for our fits for analytic free energy models, and to simplify our modeling we have chosen to neglect $G_{\text {elect }}$.

For lattice models, two types of defects are common, substitutions and interstitials. Due to atomic size differences, the only interstitials expected to be relevant are sulfur interstitials in $\mathrm{Cu}-\mathrm{Pd}$ phases. We calculate interstitial defect costs using the well-ordered structures Cu.cF4, Pd.cF4, $\mathrm{Cu}_{50} \mathrm{Pd}_{50} . \mathrm{cF} 4$, and $\mathrm{CuPd.cP2}$, with sulfur occupying a single interstitial site for various supercell sizes. The least unfavorable substitution, octahedral in $\mathrm{Cu}_{50} \mathrm{Pd}_{50} \cdot \mathrm{cF} 4$, lies approximately $2 \mathrm{eV}$ above the convex hull with significant distortion, and thus we expect contributions to sulfur solubility by occupation of interstitials to be negligible.

We here summarize the configurational free energy $G_{\text {config }}$ of a simple substitutional solid solution model, valid in the dilute limit. In a substitutional solid solution, we have a set of site classes $\mathrm{i}$, each with $\mathrm{N}_{\mathrm{i}}$ sites, an associated enthalpic cost of performing a chemical substitution of species $\alpha$ into site class i, $\Delta \mathrm{E}_{\mathrm{i}, \alpha}$, and a substitution concentration of $\mathrm{x}_{\mathrm{i}, \alpha}$. In the substitutional solid solution model, it is assumed that each substitution is uncorrelated with all other chemical substitutions, and all spatial configurations have identical energies. This implies a linear dependence of $\Delta H$ with respect to composition, 
giving an enthalpic contribution of

$$
\Delta H=\Delta H_{0}+\sum_{i, \alpha} x_{i, \alpha} N_{i} \Delta E_{i, \alpha},
$$

where $\Delta H_{0}$ denotes the enthalpy of the base structure with no substitutions. Including an ideal entropy of mixing

$$
\Delta S=-k_{B} \sum_{i, \alpha} N_{i}\left[x_{i, \alpha} \log \left(x_{i, \alpha}\right)+\left(1-x_{i, \alpha}\right) \log \left(1-x_{i, \alpha}\right)\right],
$$

leads to a Gibbs free energy $\Delta G=\Delta H-T * \Delta S$. Here, $\Delta \mathrm{H}_{0}$ and $\Delta \mathrm{E}_{\mathrm{i}, \alpha}$ can be determined from first-principles calculations. However, we control only the total impurity concentration for a species $\alpha, \mathrm{x}_{\alpha}$, not the number of substitutions in a given site class $x_{i, \alpha}$. Since we work with a fixed number of sites, we fix the total concentration of substitutions, and thus minimize the free energy over all $\mathrm{x}_{\mathrm{i}, \alpha}$ subject to the constraint of species number conservation.

To better elucidate the model, we restrict to the special case where only one type of substitution (with an enthalpic cost of $\Delta E$ ) is allowed in only one sublattice containing $N_{0}$ sites. A case with two sublattices will be considered later. Other special cases include the binary regular solution model $\left(N=N_{0}\right.$, where $N$ is the total number of atoms) and the well-known binary ideal solution model $\left(N=N_{0}, \Delta E=0\right)$. The configurational free energy takes the form

$$
\Delta G\left(N^{\prime}, T\right)=\Delta H_{0}+\Delta E * N^{\prime}+k T N_{0}\left(x^{\prime} \log x^{\prime}+\left(1-x^{\prime}\right) \log \left(1-x^{\prime}\right)\right)
$$

where $N^{\prime}$ is the number of substitutions performed and $x^{\prime}=N^{\prime} / N_{0}$ is the concentration of substitutions in the sublattice. The appropriate quantity to consider for thermodynamics is the free energy per atom, $\Delta g=\Delta G / N$, expressed in terms of the $x=N^{\prime} / N$, which can be shown to be

$$
\Delta g(x, T)=\Delta h_{0}+\Delta E * x-T \Delta S
$$

where $\Delta h_{0}=\Delta H_{0} / N$, and $\gamma=N_{0} / N$ is a measure of the number density of sublattice sites. Of particular importance is the entropic contribution to the free energy,

$$
-T \Delta S=k_{B} T \gamma(x \log x+(\gamma-x) \log (\gamma-x)-\gamma \log \gamma)
$$


which we use for all phases modeled throughout this paper.

In order for a given substitution type to appreciably affect the free energy, the two necessary features are large $\gamma$ values, corresponding to a sublattice dense in the total lattice and thus a significant entropic contribution from the sublattice, and small positive (or any negative) enthalpic cost $\Delta h_{0}$ for the substitutions, such that at a given temperature the entropic portion of the free energy can overcome the enthalpic cost (or reinforce the enthalpic gain).

We use VASP (the Vienna Ab-Initio Simulation Package) [14, 15] a plane wave ab-initio package implementing PAW potentials [16] to determine total energies. Previous work by $\mathrm{Hu}$ et al. [17] compared the accuracy of different pseudopotentials in the Pd-S system, and recommended PBEsol [18] as most suitable for calculations involving sulfur. The total energy calculations were performed by fully relaxing atomic positions and lattice parameters until energies converged to within $0.1 \mathrm{meV} /$ atom. Subsequent convergence in k-point density was performed. A common energy cutoff of $273 \mathrm{eV}$ was used. In order to model solubility ranges, calculations were performed both in unit cells and larger supercells. All phonon calculations were done using density functional perturbation theory, and were performed in at least a $2 \times 2 \times 2$ supercell of the unit cell, with the exception of $\mathrm{Pd}_{16} \mathrm{~S}_{7}$.cI46, where due to its large size only a $2 \times 2 \times 2$ supercell of the primitive cell was used. Though a supercell method with chemical ordering is being used to model phonon free energies for certain disordered phases, Wu et al [19] found that the high-temperature vibrational entropy difference between $\mathrm{L} 1_{2}$ and SQS8 configurations is only $0.03 k_{B}$, within their margin of error and corresponding to an upper bound on the free energy difference of $2.6 \mathrm{meV} /$ atom at $1000 \mathrm{~K}$. Table 1 shows a list of structures and their total energies. 


\begin{tabular}{|c|c|c|c|c|c|c|}
\hline Phase & Pearson Symbol & Prototype & Group \# & Space Group & $\Delta \mathrm{H}$ & $\mathrm{dE}$ \\
\hline $\mathrm{Cu}[20]$ & $\mathrm{cF} 4$ & $\mathrm{Cu}$ & 225 & Fm̄̄m & 0 & 0 \\
\hline $\mathrm{Pd}[21]$ & $\mathrm{cF} 4$ & $\mathrm{Cu}$ & 225 & Fm̄ $\overline{3}$ & 0 & 0 \\
\hline $\mathrm{S}_{2}$ Dimer & $\mathrm{N} / \mathrm{A}$ & $\mathrm{N} / \mathrm{A}$ & $\mathrm{N} / \mathrm{A}$ & $\mathrm{N} / \mathrm{A}$ & 0 & 0 \\
\hline $\mathrm{Cu}_{3} \mathrm{Pd}[22]$ & tP28 & $\mathrm{Cu}_{3} \mathrm{Pd}$ & 99 & $\mathrm{P} 4 \mathrm{~mm}$ & -103.0 & 0 \\
\hline $\mathrm{CuPd}$ & $\begin{array}{c}\mathrm{cP} 2 \\
\end{array}$ & $\mathrm{ClCs}$ & 221 & $\mathrm{Pm} \overline{3} \mathrm{~m}$ & -116.9 & 0 \\
\hline $\mathrm{Cu}_{2} \mathrm{~S}[23,24]$ & $\mathrm{mP} 144$ & $\mathrm{Cu} 2 \mathrm{~S}$ & 14 & $\mathrm{P} 2_{1} / \mathrm{c}$ & -496.4 & $\overline{0}$ \\
\hline $\mathrm{CuS}[25]$ & $\mathrm{oC} 24$ & $\mathrm{CuS}$ & 63 & Cmcm & -715.4 & 0 \\
\hline $\mathrm{CuS}_{2}[26]$ & $\mathrm{cP} 12$ & $\overline{\mathrm{FeS}_{2}}$ & 205 & $\mathrm{~Pa} \overline{3}$ & -821.5 & 0 \\
\hline $\mathrm{Pd}_{4} \mathrm{~S}[27]$ & $\mathrm{tP} 10$ & $\mathrm{Pd}_{4} \mathrm{Se}$ & 114 & $\mathrm{P} \overline{4} 2_{1} \mathrm{C}$ & -418.9 & 0 \\
\hline $\mathrm{Pd}_{16} \mathrm{~S}_{7}[28]$ & $\mathrm{cI} 46$ & $\mathrm{Pd}_{16} \mathrm{~S}_{7}$ & 217 & $\mathrm{I} \overline{4} 3 \mathrm{~m}$ & -589.7 & 0 \\
\hline PdS [29] & tP16 & $\mathrm{PdS}$ & 84 & $\mathrm{P} 4_{2} / \mathrm{m}$ & -892.8 & 0 \\
\hline $\mathrm{PdS}_{2}[30]$ & $\mathrm{oP} 12$ & $\mathrm{PdSe}_{2}$ & 61 & Pbca & -952.4 & 0 \\
\hline $\mathrm{CuS}$ [25] & hP12 & $\mathrm{CuS}$ & 120 & $\mathrm{I} \overline{4} \mathrm{c} 2$ & -712.9 & 2.5 \\
\hline $\mathrm{Cu}_{2} \mathrm{~S}[31]$ & tP12 & $\mathrm{Cu}_{2} \mathrm{~S}$ & 96 & $\mathrm{P} 4_{3} 2_{1} 2$ & -479.3 & 3.3 \\
\hline $\mathrm{Cu}_{4} \mathrm{Pd}[32]$ & $\mathrm{cP} 4$ & $\mathrm{AuCu}_{3}$ & 221 & $\mathrm{Pm} \overline{3} \mathrm{~m}$ & -99.7 & 3.4 \\
\hline $\mathrm{Pd}_{3} \mathrm{~S}[33]$ & oC16 & $\mathrm{Pd}_{3} \mathrm{~S}$ & 40 & Ama2 & -492.8 & 8 \\
\hline $\mathrm{Cu}_{50} \mathrm{Pd}_{50}[34]$ & $\mathrm{cF} 4$ & $\mathrm{Cu}$ & 225 & Fm $3 \mathrm{~m}$ & -106.9 & 10 \\
\hline $\mathrm{Cu}_{4} \mathrm{Pd}[35]$ & $\mathrm{tP} 20$ & $\mathrm{Cu} 4 \mathrm{Pd}$ & 84 & $\mathrm{P} 4_{2} / \mathrm{m}$ & -69.6 & 12.8 \\
\hline $\mathrm{Cu}_{2} \mathrm{Pd}_{3} \mathrm{~S}_{4}$ & $\mathrm{mP} 18$ & $\mathrm{Cu}_{2} \mathrm{Pd}_{3} \mathrm{Se}_{4}$ & 14 & $\mathrm{P} 21 / \mathrm{c}$ & -743.0 & 13.2 \\
\hline $\mathrm{Cu}_{2} \mathrm{~S}[36]$ & $\mathrm{cF} 12$ & $\mathrm{CaF}_{2}$ & 225 & $\mathrm{Fm} \overline{\mathrm{3}} \mathrm{m}$ & -503.1 & 20.6 \\
\hline $\mathrm{Cu}$ & $\mathrm{cI} 2$ & $\mathrm{~W}$ & 229 & $\operatorname{Im} \overline{3} \mathrm{~m}$ & 36.3 & 36.3 \\
\hline
\end{tabular}

Table 1: A partial list of calculated structures, focusing on "base" structures with no substitutions. All energetic quantities are given in units of $\mathrm{meV} /$ atom. $\mathrm{Cu}_{2} \mathrm{Pd}_{3} \mathrm{~S}_{4}$ is a hypothetical structure based on $\mathrm{Cu}_{2} \mathrm{Pd}_{3} \mathrm{Se}_{4} \cdot \mathrm{mP} 18$ [37]. Cu.cI2 is a hypothetical structure used to model the $\beta$-CuPd phase. $\Delta \mathrm{H}$ and $\mathrm{dE}$ are defined in eqs. 7 and 8 


\section{Results and Discussion}

\subsection{Phase Diagrams}

Given total energies, we calculate the enthalpy of formation for our structures at $\mathrm{T}=0 \mathrm{~K}$,

$$
\Delta h=\Delta h_{0}-\sum_{i} x_{i} \Delta h_{i},
$$

where $\Delta \mathrm{h}_{0}$ is the calculated $\mathrm{T}=0 \mathrm{~K}$ total energy for the base structure, $x_{i}$ is the composition of a given species $i$ in the structure, and $\Delta h_{i}$ is the $\mathrm{T}=0 \mathrm{~K}$ total energy for pure species $i$ in a chosen reference structure. By convention, this reference structure is chosen to be the equilibrium structure at $T=0 \mathrm{~K}$, so that at $\mathrm{T}=0 \mathrm{~K}$ all enthalpies of formation for the pure species vanish. In the $\mathrm{Cu}-\mathrm{Pd}-\mathrm{S}$ system, the standard reference structures would be Cu.cF4 for copper, Pd.cF4 for palladium, and S.mP48 for sulfur.

As we are interested in interaction of gaseous sulfur with copper-palladium membranes, we have chosen to use gaseous sulfur dimers rather than the standard S.mP48 when calculating phase diagrams. In the case of the ternary phase diagram, all structures of interest have relatively low sulfur composition, so the mismatch in reference phase compared to experimental phase diagrams is negligible.

The quantity of importance for constructing temperature dependent phase diagrams is

$$
d E=\Delta h-[\Delta h],
$$

where $[\Delta \mathrm{h}]$ is the enthalpy of formation of the convex hull at a structure's stoichiometry. By definition, this quantity is non-negative, and it vanishes only when the structure lies on the convex hull. This quantity is a measure of how far above the convex hull a particular structure lies at $\mathrm{T}=0 \mathrm{~K}$. Structures with large dE's require large entropic contributions to free energy in order to overcome enthalpic costs.

Figure 1 shows the $\mathrm{T}=0 \mathrm{~K}$ binary enthalpies of formation. Observe that palladium and sulfur react strongly, as can be seen by the maximum enthalpy of 


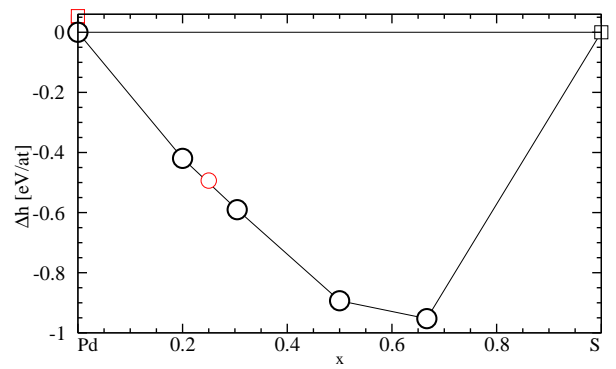

(a) $\mathrm{Pd}-\mathrm{S}$

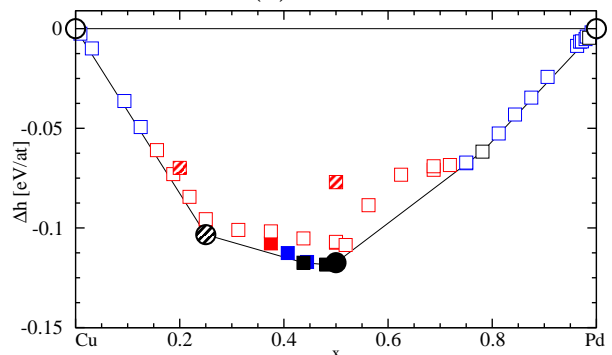

(c) $\mathrm{Cu}-\mathrm{Pd}$

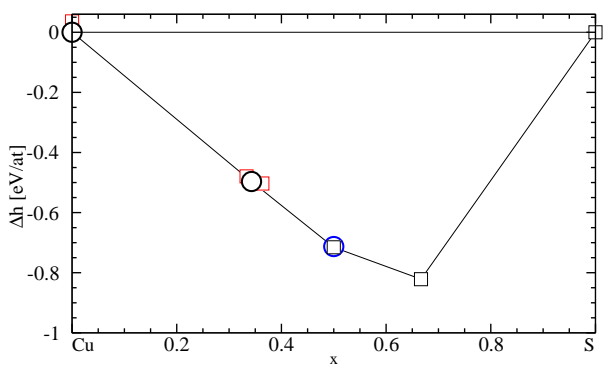

(b) $\mathrm{Cu}-\mathrm{S}$

Figure 1: (color online) Binary enthalpies of formation for $\mathrm{Pd}-\mathrm{S}, \mathrm{Cu}-\mathrm{S}$, and $\mathrm{Cu}-\mathrm{Pd}$. The $\mathrm{x}$ axis corresponds to concentration, and $\mathrm{y}$ axis corresponds to enthalpy of formation. Black symbols denote stable structures, blue correspond to structures witin $3 \mathrm{meV}$ of the convex hull, and red to structures above $3 \mathrm{meV}$. Circles with thick borders are known low temperature stable structures, circles with thin borders are known high temperature stable structures, and squares denotes all other cases (including hypothetical structures). For $\mathrm{Cu}-\mathrm{Pd}$, to better distinguish phases, filled symbols correspond to bcc structures, empty symbols to fcc, and dashed for the three other structures $\left(\mathrm{Cu}_{3} \mathrm{Pd} . \mathrm{PP} 28, \mathrm{Cu}_{4} \mathrm{Pd} . \mathrm{PP} 20\right.$, and the SQS configuration for fcc at $50 \% \mathrm{Pd}$ ). 
formation of $0.95 \mathrm{eV} /$ atom. This strong enthalpy of formation reflects the tendency of pure palladium membranes to sulfidize. Next, copper and sulfur react almost as strongly, with a maximum enthalpy of formation of $0.82 \mathrm{eV} /$ atom. Finally, copper and palladium have a maximum enthalpy of formation of only $0.12 \mathrm{eV} /$ atom, indicating that the interspecies binding between copper and palladium is relatively weak. This is expected from the $\mathrm{Cu}-\mathrm{Pd}$ phase diagram, as all known phases are variants of fcc (the $\mathrm{T}=0, \mathrm{p}=0$ structure for both $\mathrm{Cu}$ and $\mathrm{Pd}$ ) or bcc (which is reached from fcc by a martensic transition [38]). We find that the known structure CuS.oC24 is mechanically unstable, with an imaginary phonon mode that stabilizes a slight monoclinic distortion, and this distorted monoclinic structure, CuS.mC24, is the true ground state structure according to DFT. The stable phases predicted correspond to known low temperature stable phases, with the exception of $\mathrm{CuS}_{2} . \mathrm{tP} 12$, which is not observed stable at temperatures as low as $300 \mathrm{~K}$ (its stability is mostly likely due to the use of $\mathrm{S}_{2}$ as a reference structure), and $\mathrm{CuS} . \mathrm{mC} 24$, the experimentally observed stable structure being CuS.hP12.

Experimental results [6] show $\mathrm{Pd}_{16} \mathrm{~S}_{7}$.cI46 and $\mathrm{Pd}_{4} \mathrm{~S}$.tP10 having solubility ranges for copper, which implies the existence of substitutional or interstitial defects. $\mathrm{Pd}_{16} \mathrm{~S}_{7}$.cI46 contains four Wyckoff site classes: $8 \mathrm{c}$ and $24 \mathrm{~g}$ sites containing palladium and $8 \mathrm{c}$ and $6 \mathrm{~b}$ sites containing sulfur (see Fig. 2). For $\mathrm{Pd}_{4} \mathrm{~S} . \mathrm{tP} 10$ there are only two site classes, an $8 \mathrm{~g}$ containing palladium and $2 \mathrm{a}$ containing sulfur.

Shown in Figure 3 is our calculated $\mathrm{T}=0 \mathrm{~K}$ phase diagram for the $\mathrm{Cu}-\mathrm{Pd}-\mathrm{S}$ system (supporting data is in Table 2). We find the $8 \mathrm{c}$ site class in $\mathrm{Pd}_{16} \mathrm{~S}_{7}$ is favorable to copper substitution. At $\mathrm{T}=0 \mathrm{~K}$ it is enthalpically favorable to occupy 6 of the 8 possible lattice sites, with a sudden upturn for further filling of the $8 \mathrm{c}$ site class. The only other substitutions that are found favorable are $\mathrm{S}$ and $\mathrm{Cu}$ in $\beta$-CuPd, $\mathrm{Cu}$ in $\mathrm{Pd} . c F 4$, and $\mathrm{Pd}$ in $\mathrm{CuS}_{2}$. Substitutions of $\mathrm{Cu}$ in the $\beta$-CuPd phase have a solubility range from $50 \% \mathrm{Cu}$ to $55.5 \%$ at $\mathrm{T}=0 \mathrm{~K}$. We find the $\beta$-CuPd phase is only favorable to $\mathrm{Cu}$ substitutions on the $\mathrm{Pd}$ sublattice, and not $\mathrm{Pd}$ substitutions on the $\mathrm{Cu}$ sublattice, which is experimentally supported by 


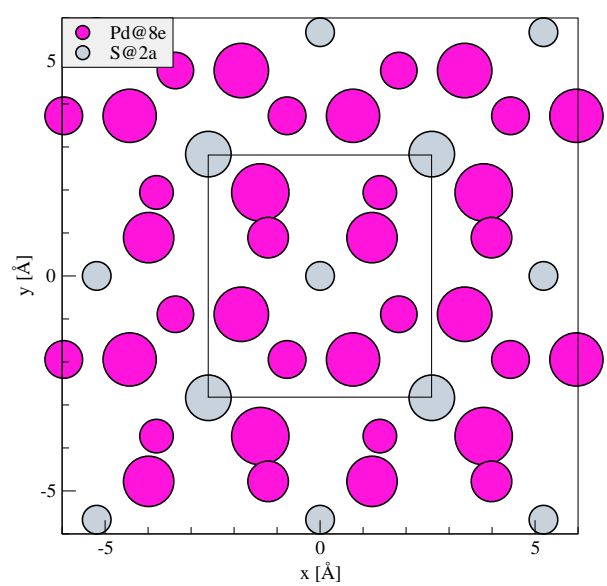

(a) $\mathrm{P}_{4} \mathrm{~S} . \mathrm{tP} 10$

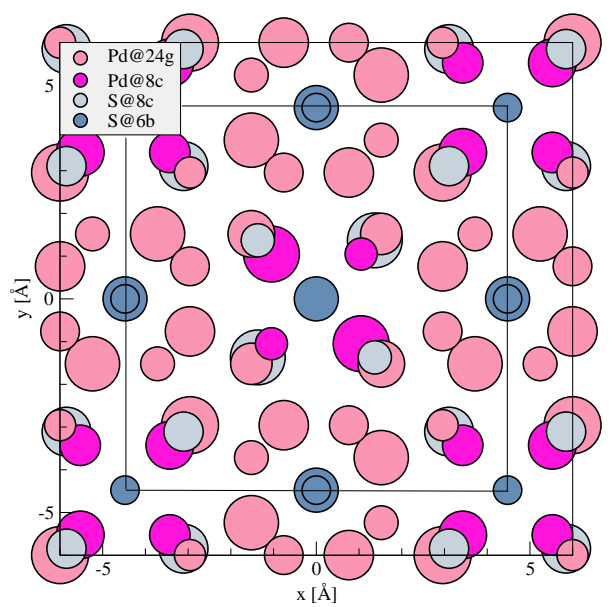

(b) $\mathrm{P}_{16} \mathrm{~S}_{7} . \mathrm{cI} 46$

Figure 2: (color online) Crystal structures for $\mathrm{P}_{4} \mathrm{~S} . t \mathrm{P} 10$ and $\mathrm{P}_{16} \mathrm{~S}_{7} . c \mathrm{I} 46$. The unit cells are outlined. Atomic sizes indicate vertical height.

observations that the palladium content of $\beta$-CuPd never exceeds $50 \%$. As none of the $\mathrm{Cu}$ - and $\mathrm{Pd}$ - rich structures are in competition with $\mathrm{CuS}_{2} \cdot \mathrm{tP} 12$, and the entropic contribution is small, we ignore substitutions in $\mathrm{CuS}_{2} . \mathrm{tP} 12$. We also find a small sulfur solubility range in the $\mathrm{Cu}$ sublattice of $\beta$ - $\mathrm{CuPd}$ at $\mathrm{T}=0 \mathrm{~K}$, which is supported by experimental phase diagrams at $\mathrm{T}=673 \mathrm{~K}$ and $\mathrm{T}=823 \mathrm{~K}$.

While these are the only stable $\mathrm{T}=0 \mathrm{~K}$ substitutions, we expect that at higher temperatures, substitutions into other sites that had suitably low enthalpic cost will be stabilized by entropy: PdS.tP16 (2c), $\mathrm{Pd}_{16} \mathrm{~S}_{7} . \mathrm{cI} 46$ (24g), and $\mathrm{Pd}_{4} \mathrm{~S} . \mathrm{PP} 10$ (8e) sites being possible candidates (see Table 2). However, we chose to exclude modeling the PdS.tP16 2c substitution range, as due to the small concentration of 2c sites in PdS.tP16, combined with competition with other phases with strong entropic effects, we expect the concentration range to be negligible.

To determine solubility ranges more precisely, we model phases analytically (see Table 3), using first principles calculation data to suggest suitable enthalpic models. All models are based off the regular solution model, though with modifications to better reflect the behavior of the phase. We choose the models to smooth out fluctuations in the first principles calculated energies while still 
keeping the essential trends seen intact. The phases modeled are $\mathrm{Pd}_{4} \mathrm{~S}, \mathrm{Pd}_{16} \mathrm{~S}_{7}$, $\beta$-CuPd, and the $\mathrm{CuPd}-\mathrm{FCC}$ phase. In all cases we use the ideal entropy (Eq. 6) for sublattice filling. Our model for $\mathrm{Pd}_{16} \mathrm{~S}_{7}$ differs from a regular solution model in that we use a piecewise linear function (see Fig. 6) for the enthalpic part of the free energy. The enthalpic contribution to the free energy of $\mathrm{Pd}_{16} \mathrm{~S}_{7}$ is increasingly favorable up to 6 substitutions $(\mathrm{x}=0.13)$ on the $8 \mathrm{c}$ sublattice, but from 6 to 8 substitutions $(\mathrm{x}=0.174)$ the favorability is reduced. Previous crystallographic work by Matkovic [28] observed a crystalline phase of $\mathrm{Pd}_{16} \mathrm{~S}_{7}$ with $14 \% \mathrm{Cu}$ concentration, the $\mathrm{Cu}$ occupying $8 \mathrm{c}$ sites. However this work was performed at $853 \mathrm{~K}$ and did not suggest any mechanism by which these substitutions are stabilized. For $\mathrm{Pd}_{4} \mathrm{~S}$, we use the dilute limit form of the regular solution model $(1-x \approx 1)$, though it was necessary to add a small quadratic term to the free energy to fit our first principle results. Both CuPd-FCC and $\beta$-CuPd were fit using a first-order regular solution model, with CuPd-FCC having the entire lattice available for substitution, allowing usage of the standard form of a regular solution model. $\beta$-CuPd has only the Pd sublattice available for substitution by $\mathrm{Cu}$, which may be modeled using a regular solution model by replacing terms involving $x$ with terms involving $x-0.5$, where $x$ denotes the $\mathrm{Cu}$ concentration. We also compute a SQS configuration for fcc at $50 \mathrm{Pd} \%[39]$ with purely random correlations until the 8 th nearest neighbor and find it lies above the convex hull by $40 \mathrm{meV} /$ atom.

Experimental phase diagrams show a sulfur solubility range near $\mathrm{Cu}_{0.5} \mathrm{Pd}_{0.5}$ trending in the palladium-rich direction. We find dilute $\mathrm{S}$ substitutions onto the $\mathrm{Cu}$ sublattice in $\beta$ - $\mathrm{CuPd}$, creating a phase trending in the palladium-rich direction, are stable at $\mathrm{T}=0 \mathrm{~K}$. Subsequent substitutions become rapidly unfavorable. From this, we expect limited entropic stabilization of additional substitutions of $\mathrm{S}$ in $\beta$-CuPd at higher temperatures, leading to a roughly constant solubility range.

To include phonon free energy in solid solution phases, we calculate phonon free energies in the harmonic approximation at well-ordered configurations at select compositions and linearly interpolate between these compositions across 


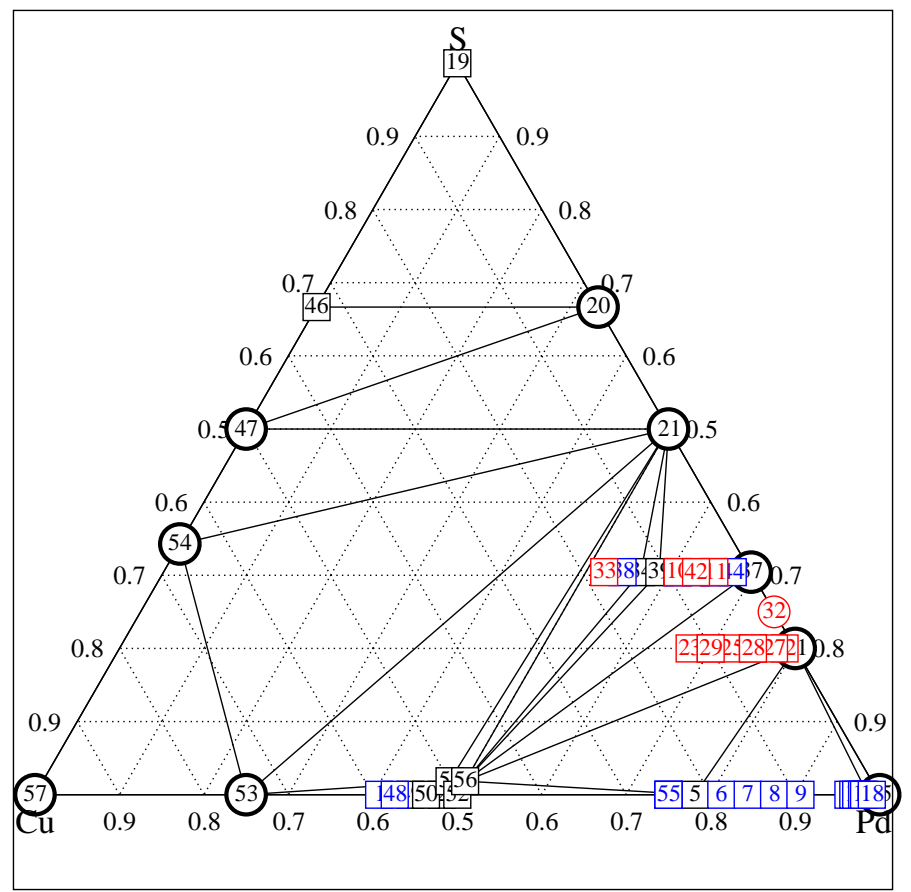

Figure 3: (color online) The calculated $\mathrm{T}=0 \mathrm{~K}$ phase diagram for the $\mathrm{Cu}-\mathrm{Pd}-\mathrm{S}$ system. Plotting symbols as in Fig. 1.

the phase region. To model the free energy of gaseous sulfur, we use empirical data taken from the NIST-JANAF tables, as explained later in the paper.

Figures 4 and 5 compare our calculated phase diagrams with experiment for $\mathrm{T}=673 \mathrm{~K}$ and $823 \mathrm{~K}$, respectively. Our $\mathrm{T}=673 \mathrm{~K}$ phase diagram matches the experimental results qualitatively. Note, however, that the " $\mathrm{Cu}_{2-\mathrm{x}} \mathrm{S}$ " region of the experimental phase diagram contains multiple structures, many of which are non-stoichiometric, whereas ours contains only one structure. The phase labeled " $\mathrm{Cu}_{3} \mathrm{Pd} "$ (or 1D LPS) has a slight solubility range experimentally whereas we model it as a well-ordered line compound. Our $\mathrm{T}=823 \mathrm{~K}$ diagrams show more 


\begin{tabular}{|c|c|c|c|c|}
\hline Base Structure & Site Class & $\begin{array}{c}\text { Chemical Species } \\
\text { Change }\end{array}$ & $\begin{array}{c}\text { Enthalpic Cost } \\
(\mathrm{meV} / \text { atom })\end{array}$ & $\begin{array}{c}\text { Maximum Impurity Concentration } \\
\text { in Site Class }\end{array}$ \\
\hline$\beta$-CuPd & $2 \mathrm{a}$ & $\mathrm{Pd}$ to $\mathrm{Cu}$ & 0 & 12.5 \\
\hline$\beta$-CuPd & $2 \mathrm{a}$ & $\mathrm{Cu}$ to $\mathrm{S}$ & 0 & 3.8 \\
\hline$\beta$-CuPd & $2 \mathrm{a}$ & $\mathrm{Pd}$ to $\mathrm{S}$ & 0 & 3.8 \\
\hline $\mathrm{Pd}$.cF4 & $4 \mathrm{a}$ & $\mathrm{Cu}$ to $\mathrm{Pd}$ & 0 & 21.9 \\
\hline $\mathrm{Pd}_{16} \mathrm{~S} 7 \cdot \mathrm{cI} 46$ & $8 \mathrm{c}$ & $\mathrm{Pd}$ to $\mathrm{Cu}$ & 0 & 12.5 \\
\hline $\mathrm{Pd}_{16} \mathrm{~S}_{7} \cdot \mathrm{cI} 46$ & $24 \mathrm{~g}$ & $\mathrm{Pd}$ to $\mathrm{Cu}$ & 12.9 & 3.33 \\
\hline $\mathrm{Pd}_{4} \mathrm{~S} \cdot \mathrm{PP} 10$ & $8 \mathrm{e}$ & $\mathrm{Pd}$ to $\mathrm{Cu}$ & 4.7 & 6.13 \\
\hline $\mathrm{CuS}_{2} \cdot \mathrm{cP} 12$ & $4 \mathrm{a}$ & $\mathrm{Cu}$ to $\mathrm{Pd}$ & 0 & 50.00 \\
\hline $\mathrm{PdS}$.tP16 & $2 \mathrm{c}$ & $\mathrm{Pd}$ to $\mathrm{Cu}$ & 5.3 & \\
\hline
\end{tabular}

Table 2: A list of substitutions into binary structures to produce ternary structures. Only low enthalpic cost substitutions are shown. Impurity concentration denotes the concentration in the appropriate sublattice, not concentration in the structure as a whole.

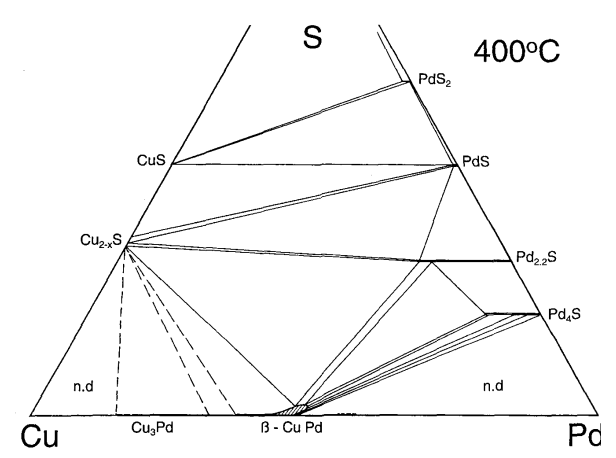

(a) Experimental, $\mathrm{T}=673 \mathrm{~K}$

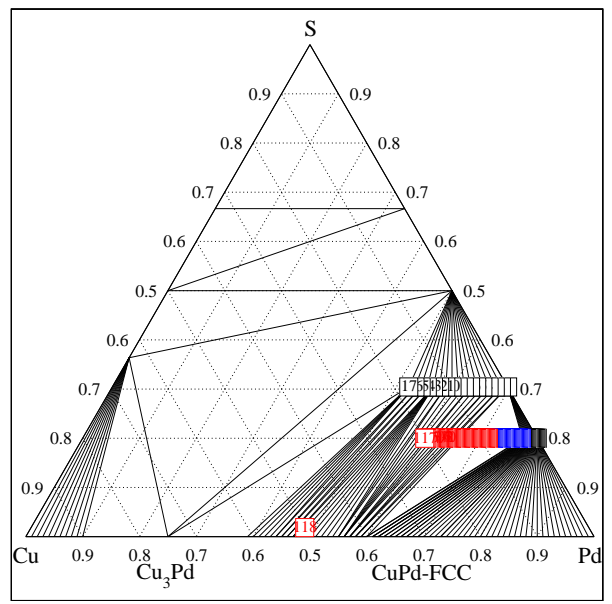

(b) Calculated, $\mathrm{T}=673 \mathrm{~K}$

Figure 4: (color online) The experimental phase diagram for the $\mathrm{Cu}-\mathrm{Pd}-\mathrm{S}$ system at $\mathrm{T}=673 \mathrm{~K}$, and our calculated phase diagram. 


\begin{tabular}{|c|c|c|c|c|}
\hline Phase & $\begin{array}{c}\text { Substitution Type } \\
(\mathrm{Cu} \text { Composition Range })\end{array}$ & $\gamma$ & Phonon Concentrations & $\begin{array}{c}h_{\text {config }} \\
(\mathrm{eV} / \text { atom })\end{array}$ \\
\hline $\mathrm{Pd}_{4} \mathrm{~S}$ & $\mathrm{Cu} @ \mathrm{Pd} 8 \mathrm{e}(0-0.8)$ & $8 / 10$ & $0,0.8$ & $-5.350+1.612 x+0.225 x^{2}$ \\
\hline $\mathrm{Pd}_{16} \mathrm{~S} 7$ & $\mathrm{Cu} @ \mathrm{Pd} 8 \mathrm{c}(0-0.175)$ & $8 / 46$ & $0,0.175$ & $-5.237+1.445 x(x<6 / 46),-5.251+1.554 x(x>=6 / 46)$ \\
\hline$\beta$-CuPd & $\mathrm{Cu} @ \mathrm{Pd} 2 \mathrm{a}(0.5-1)$ & $1 / 2$ & $0.5,1$ & $-4.8575+1.773(x-0.5)+(x-0.5)(1-x)(-0.206(x-0.5)-1.526(1-x))$ \\
\hline $\mathrm{CuPd}-\mathrm{FCC}$ & $\mathrm{Cu} @ \mathrm{Pd} 4 \mathrm{a}(0-1)$ & 1 & $0,0.50,0.75,1$ & $-5.477+1.469 x+x(1-x)(-0.529 x-0.267(1-x))$ \\
\hline
\end{tabular}

Table 3: Description of our phase models. $\gamma$ denotes the number concentration of the sublattice in the total lattice and is used for scaling the entropic contribution to energy (see equation 6). "Phonon concentrations" denotes the concentrations for which phonon free energies were calculated. $x$ denotes the copper composition. 


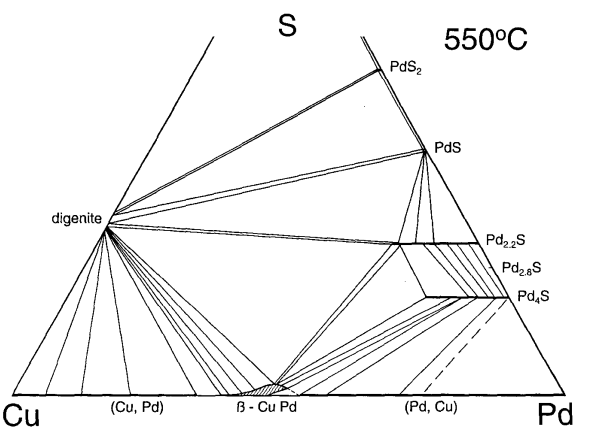

(a) Experimental, $\mathrm{T}=823 \mathrm{~K}$

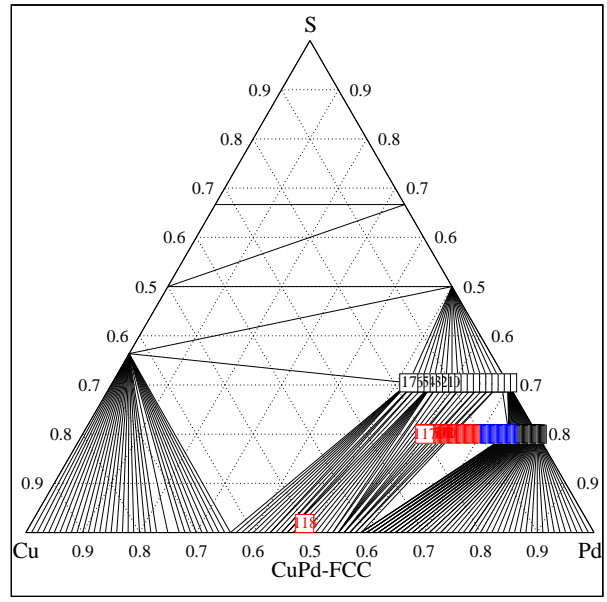

(b) Calculated, $\mathrm{T}=823 \mathrm{~K}$

Figure 5: (color online) The experimental phase diagram for the $\mathrm{Cu}-\mathrm{Pd}-\mathrm{S}$ system at $\mathrm{T}=823 \mathrm{~K}$, and our calculated phase diagram.

disagreement, as there is only one $\mathrm{Cu}-\mathrm{S}$ structure that is stable and a $\mathrm{Pd}_{3} \mathrm{~S}$ structure is stabilized at this temperature. More recent phase diagrams have $\mathrm{Pd}_{3} \mathrm{~S}$ being stabilized at $\mathrm{T}=829 \mathrm{~K}$, however. This is likely due to entropic effects other than configurational and phononic (in the harmonic approximation) that were not included. As can be seen, $\mathrm{Pd}_{3} \mathrm{~S}$ is part of our collection of calculated structures but is not a stable low-temperature phase. At both temperatures we attempt to model sulfur solubility in the $\beta$-CuPd phase but find sulfur solubility to be unstable at temperatures of interest. This is surprising, as our $\mathrm{T}=0 \mathrm{~K}$ phase diagram has a sulfur solubility range in $\beta$ - $\mathrm{CuPd}$ similar in shape to what is experimentally observed at higher temperatures, and the enthalpic behavior of our sulfur substitutions supports the observed temperature independence of the sulfur solubility range.

The $\mathrm{Pd}_{16} \mathrm{~S}_{7}$.cI46 copper solubility range is not appreciably affected by the temperature, as it is dominated by enthalpy rather than entropy. The $24 \mathrm{~g}$ site is unfavorable for copper substitution. The high multiplicity of the $24 \mathrm{~g}$ site class gives a large entropic contribution to the free energy at high temperature relative to the $8 \mathrm{c}$ site class. However, we find that the enthalpic cost (see Figure 


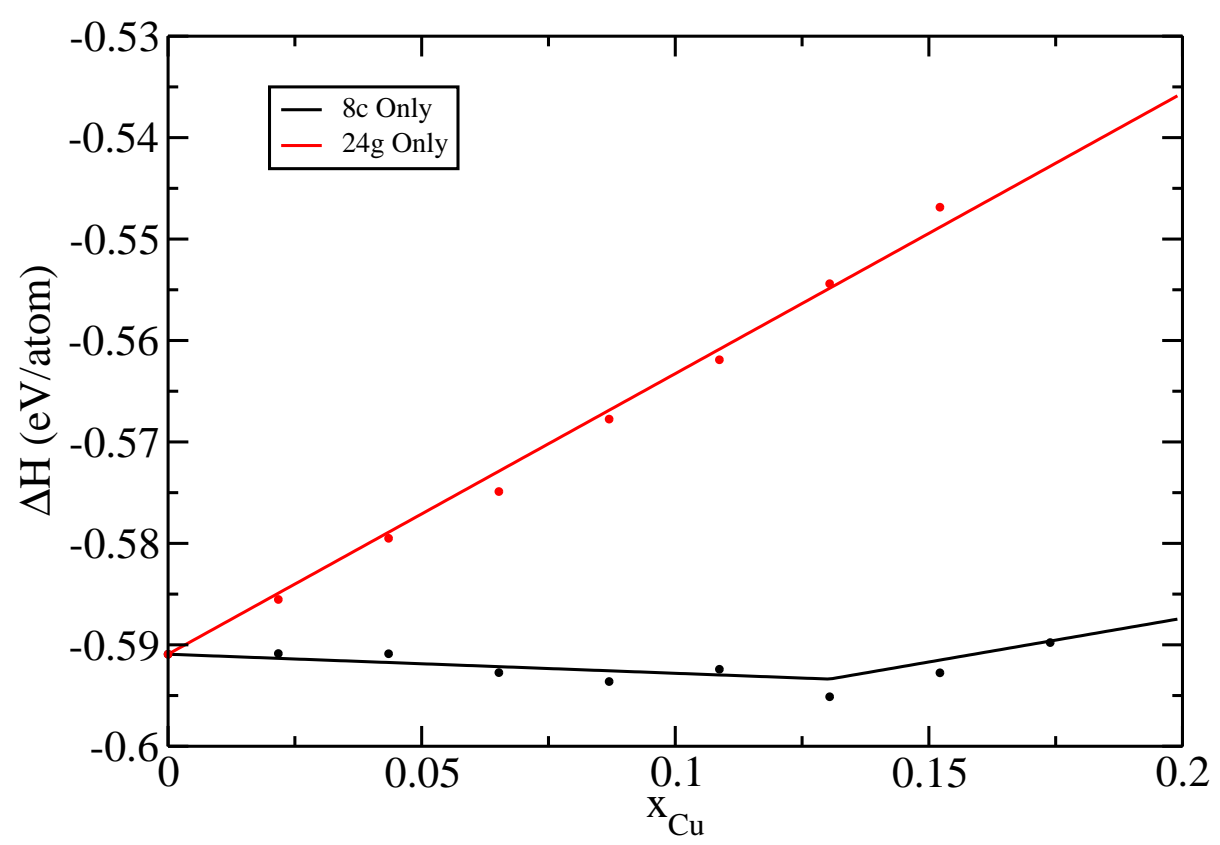

Figure 6: (color online) Comparison for the enthalpy of formations for filling $8 \mathrm{c}$ sites versus filling $24 \mathrm{~g}$ sites in $\mathrm{Pd}_{16} \mathrm{~S}_{7}$.cI46.

6) associated with occupying $24 \mathrm{~g}$ sites is too high relative to the entropic contributions at the given temperatures and only affects the solubility range by $1 \%$ to $2 \%$. Thus the solubility range consists almost completely of $8 \mathrm{c}$ sites and is inappreciably affected by temperature. For this reason, our model (Table 3) only includes $8 \mathrm{c}$ sites and not $24 \mathrm{~g}$ sites. For $\mathrm{Pd}_{16} \mathrm{~S}_{7}$.cI46, at both measured temperatures the experimental copper solubility limit is $20 \%$, and our calculated value is $17.5 \%$, the mismatch likely due to $\mathrm{Cu}$ occupation of $24 \mathrm{~g}$ sites. Our results explain why this solubility range appears to be independent of temperature; it is not stabilized due to entropic contributions but due to enthalpy arising from details of the electronic structure (see subsection 3.2).

In contrast, $\mathrm{Cu}$ substitutions in $\mathrm{Pd}_{4} \mathrm{~S}$.tP10 are not enthalpically favorable at $\mathrm{T}=0 \mathrm{~K}$ but are entropically stabilized at higher temperature. As can be seen in the above phase diagrams, the copper solubility for $\mathrm{Pd}_{4} \mathrm{~S}$.tP10 is temperaturedependent in both the calculated and experimental work. While our results 
agree qualitatively with experimental results, there is still a discrepancy in the copper solubility range. For $\mathrm{Pd}_{4} \mathrm{~S} . \mathrm{PP} 10$, at $\mathrm{T}=673 \mathrm{~K}$ the experimental value is $12.7 \%$ and ours is $2.5 \%$, and for $\mathrm{T}=823 \mathrm{~K}$ the values are $18.6 \%$ and $5 \%$ respectively. Solid solution models overestimate the configurational entropy, as including correlations between substitutions will alter the energies of distinct configurations with the same composition and reduce the multiplicity. We have thus overestimated the entropy of the $\mathrm{Pd}_{16} \mathrm{~S}_{7}$ phase, whose solubility range extends to almost complete filling of the $8 \mathrm{c}$ site, relative to the $\mathrm{Pd}_{4} \mathrm{~S}$ phase, whose filling in the $8 \mathrm{e}$ sublattice is sparse. Thus we would expect more accurate free energy models will lead to decreased entropy in the $\mathrm{Pd}_{16} \mathrm{~S}_{7}$ phase with comparatively small changes in $\mathrm{Pd}_{4} \mathrm{~S}$, increasing the solubility range of $\mathrm{Pd}_{4} \mathrm{~S}$. This will not affect the stability of $\mathrm{Pd}_{16} \mathrm{~S}_{7}$ as it is primarily enthalpically stabilized.

The large solubility range in the palladium rich side of the CuPd-FCC phase at $\mathrm{T}=0 \mathrm{~K}$ is also a factor in the incorrect solubility ranges for $\mathrm{Pd}_{4} \mathrm{~S} . \mathrm{P} 10$, as we have found that altering the fitting parameters for the CuPd-FCC phase appreciably affects the solubility range for $\mathrm{Pd}_{4} \mathrm{~S} . \mathrm{tP} 10$. As we also encountered an issue with sulfur solubility in $\beta$-CuPd, with the sulfur solubility range destabilizing relative to $\mathrm{CuPd}-\mathrm{FCC}$ at temperature below temperatures of interest, and we have a large solubility range on the $\mathrm{Pd}$-rich side at $\mathrm{T}=0 \mathrm{~K}$ for the $\mathrm{CuPd}-\mathrm{FCC}$ phase, it appears that one major source of error is inaccurate modeling of the CuPd-FCC phase. We will return to this issue in the activities portion of this paper.

For our $\mathrm{Cu}-\mathrm{Pd}$ binary at high temperatures, we find that $\mathrm{Cu}_{3} \mathrm{Pd} . \mathrm{tP} 28$ becomes unstable relative to the $\mathrm{CuPd}-\mathrm{FCC}$ phase at $\mathrm{T}=827 \mathrm{~K}$, and $\beta$-CuPd becomes unstable relative to $\mathrm{CuPd}-\mathrm{FCC}$ and $\mathrm{Cu}_{3} \mathrm{Pd} . \mathrm{tP} 28$ at $\mathrm{T}=536 \mathrm{~K}$ and a composition of $59.5 \%$, significantly below the experimentally observed temperature of $\mathrm{T}=871 \mathrm{~K}$ but close to the experimental composition of $58 \%$. This relative instability of $\beta$-CuPd at temperatures of interest is responsible for the observed instability of any sulfur solubility in $\beta$-CuPd in our $\mathrm{T}=673 \mathrm{~K}$ and $\mathrm{T}=823 \mathrm{~K}$ phase diagrams. We will show later that first-principles inspired corrections to the enthalpic portion of the free energy for CuPd-FCC will bring the phase transition 
closer in line with experimental results, though as CuPd-FCC phase has maximal entropy and $\beta$-CuPd phase (with only $\mathrm{Cu}$ substitutions in $\mathrm{Pd}$ sites) has minimal entropy in near the equiatomic composition region, it is likely that the assumption of ideal entropy in the FCC phase also plays a role.

But even with these discrepancies, it is clear that we have predicted major details of the $\mathrm{Cu}-\mathrm{Pd}-\mathrm{S}$ ternary phase diagram, specifically the mechanism for stabilization of the solubility ranges of $\mathrm{Pd}_{4} \mathrm{~S} . \mathrm{tP} 10$ and $\mathrm{Pd}_{16} \mathrm{~S}_{7}$ as well as details about the stability of the $\beta$-CuPd system, using only first principles calculations with no empirical fitting.

\subsection{Electronic Structure}

The question remains why the $\mathrm{Pd}_{16} \mathrm{~S}_{7}$.cI46 8c site class favors copper in the first 6 substitutions, but substitution in the final two $8 \mathrm{c}$ sites are unfavorable. Consider the constituent binaries: copper binds less strongly with sulfur than palladium, and copper binding with palladium is relatively weak, so we would expect copper substitution into $\mathrm{Pd}-\mathrm{S}$ binaries to be slightly unfavorable. If it were to turn out to be favored, then we would expect $\mathrm{Cu}$ to fully occupy the $8 \mathrm{c}$ class. First-principles methods provide electronic structure information that can resolve this issue.

Figure 7 shows the electronic densities of states for substitutions in $\mathrm{Pd}_{16} \mathrm{~S}_{7}$.cI46. Each colored solid line corresponds to the electronic density of states for a different number of substitutions in the $8 \mathrm{c}$ site class of $\mathrm{Pd}_{16} \mathrm{~S}_{7} . c \mathrm{I} 46$. It can be seen that the densities of states follow a rigid band model. Here copper is being substituted for palladium, and copper has one more electron in its valence shell than palladium. Under a rigid band model, performing a substitution adds one electron per unit cell without appreciably changing the valence electronic eigenstates, increasing the Fermi level relative to the fixed band structure.

In all cases, a pseudogap lies near the Fermi level. In the case of no substitutions, the pseudogap lies to the right of the Fermi level. As the number of copper substitutions increases, the increased electron count drive the pseudogap to the left, towards the Fermi level. At six substitutions the Fermi level 


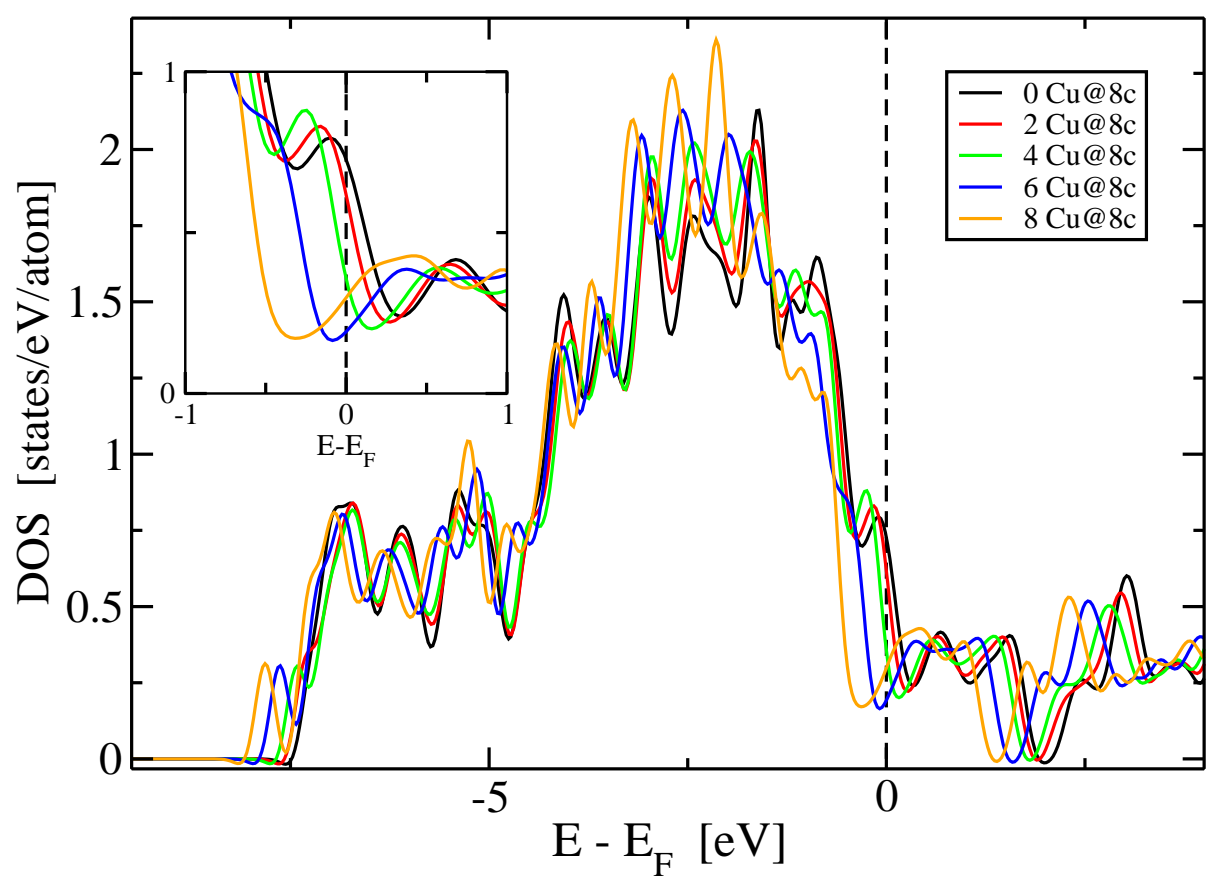

Figure 7: (color online) Calculated electronic densities of states for $\mathrm{Pd}_{16} \mathrm{~S}_{7}$.cI46 with copper substitutions at the palladium 8c sites, with the Fermi level $\mathrm{E}_{\mathrm{F}}$ (dashed line) set to zero. The inset enlarges the pseudogap region. 
lies almost directly at the minimum of the pseudogap. This is a well-known stabilization mechanism for alloys [40]. As the number of substitutions increases above six, the Fermi level is driven away from the pseudogap, destabilizing the structure and leading to the sudden increase in the enthalpy of formation (see Fig. 6). This pseudogap stabilization mechanism at $\mathrm{T}=0 \mathrm{~K}$, combined with large enthalpic cost of $24 \mathrm{~g}$ substitutions, explains the temperature independence of the $\mathrm{Pd}_{16} \mathrm{~S}_{7}$ solubility range.

\subsection{Predominance Diagrams}

We now calculate the predominance diagram for the $\mathrm{Pd}-\mathrm{S}_{2}$ system. We work with a fixed quantity of palladium interacting with a reservoir of gaseous $\mathrm{S}_{2}$, with temperature and pressure being free parameters. For an ideal gas, this implies that we control the chemical potential of the gas, and thus we work in the semi-grand canonical ensemble:

$$
\Sigma(T, p, x)=G(T, p, x)-\mu_{S_{2}} N_{S_{2}}
$$

where $\mathrm{G}$ is the previously defined Gibbs free energy, $\mu_{\mathrm{S}_{2}}$ is the chemical potential for the sulfur dimers, and $N_{S_{2}}=N_{S} / 2$ is the half the number of sulfur atoms in a given phase (as the chemical potential is for sulfur dimers). To determine sulfidization thresholds, we calculate the semi-grand canonical free energy for all phases of interest, Pd.cF4, $\mathrm{Pd}_{4} \mathrm{~S} . \mathrm{PP} 10, \mathrm{Pd}_{16} \mathrm{~S}_{7} . \mathrm{cI} 46, \mathrm{Pd}_{3} \mathrm{~S} . \mathrm{CC} 16$, and PdS.tP16. The phase with the lowest free energy will be stable. All Pdcontaining phases of interest are line compounds, containing only total energy and phonon contributions.

The chemical potential for $\mathrm{S}_{2}$ complicates the calculation, as it is a gaseous phase. We incorporate empirical results into our method, in a manner consistent with the results obtained from first principles calculations. For the free energy of the gas, we have

$$
\mu(T, p)=\mu^{0}(T)+k T \log \frac{p}{p_{0}} .
$$

Here $\mu$ is the chemical potential per molecule, $p_{0}$ is a reference pressure (by convention taken to be 1 bar, as will be done here), and $\mu^{0}$ is the chemical 
potential per molecule measured at the reference pressure,

$$
\mu^{0}(T)=h-\left.T s\right|_{p=1},
$$

where $\mathrm{H}$ and $\mathrm{S}$ are obtained from the NIST-JANAF tables [41]. $\mu^{0}$ obtained from the JANAF tables has a physically unrealistic infinite value at $\mathrm{T}=0 \mathrm{~K}$ due to the presence of $1 / \mathrm{T}$ terms in both the $\mathrm{H}$ and $\mathrm{TS}$ contributions. As shown in Figure 8, $\mu^{0}$ is nearly linear for temperatures of interest, so we fit to a linear equation using the $770 K<T<1430 K$ region to eliminate the $\mathrm{T}=0 \mathrm{~K}$ pole. There is still an issue of constant offsets to energy; the JANAF tabulated values are relative to the enthalpy at $\mathrm{T}=298 \mathrm{~K}$, and whereas all our calculated values are computed at $\mathrm{T}=0 \mathrm{~K}$. In order to incorporate the empirical data into our method, we must shift its zero of energy. In particular, at $\mathrm{T}=0 \mathrm{~K}$, we set the empirical data to match what first principles calculations would have predicted,

$$
\left.g_{S_{2}}\right|_{T=0 K}=e_{\text {config }}+\left.e_{\text {phonon }}\right|_{T=0 K} .
$$

As we have measured all energies relative to the tie-plane between pure elements, $e_{\text {config }} \equiv 0$, and so the zero-point energy $e_{\text {phonon }}$ is the only contribution at $\mathrm{T}=0 \mathrm{~K}$ taken from first principles calculations.

Shown in Table 4 are our predicted sulfidization thresholds relative to experimental predominance diagrams obtained by Taylor [42]. Predictions with and without phonon free energies are shown. It is necessary to include phonons to obtain reasonable agreement with experimental results, as when phonon free energies are excluded, the relative errors in pressure are as large as four orders of magnitude. When including phonon free energies, in all cases our pressure estimates are within a factor of 6 of experimental results. It should also be be noted that Taylor's phase boundaries are themselves based on fits from experimental enthalpy data. One difficulty is that Taylor has a liquid region in the high-temperature, low pressure region of the predominance diagram, whereas we are only interested in solid phases, so experimental thresholds from the solid regions were extrapolated to liquid regions to give numbers suitable for comparison. This extrapolation is valid as Taylor's thresholds in the solid regions 


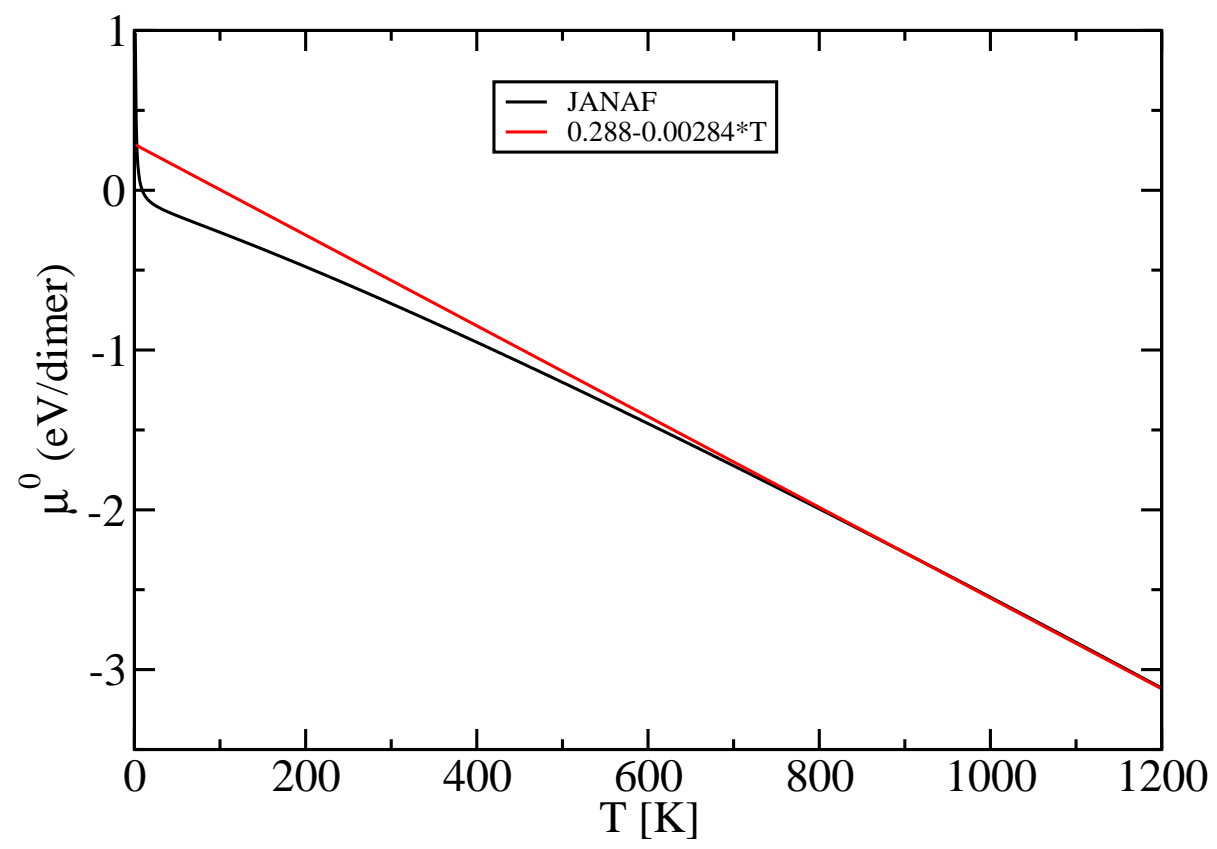

Figure 8: (color online) The chemical potential of $\mathrm{S}_{2}$ dimers. Black is NISTJANAF, and red is our linear fit.

were found to be extremely linear. Another difficulty is that $\mathrm{Pd}_{3} \mathrm{~S}$ is stable for a small pressure range in between temperatures of $830 \mathrm{~K}$ and $920 \mathrm{~K}$, and it would likely be stable for higher temperatures if not for the liquid phase, but our calculations do not predict it stable in this region. This is most likely due to errors in the phonon free energy, which as already shown appreciably affects results.

\subsection{Activity Calculations}

In this last section, the activities of species in binary $\mathrm{Cu}-\mathrm{Pd}$ are calculated, as these can be used to predict sulfidization thresholds for $\mathrm{Cu}-\mathrm{Pd}$ in the presence of S. We wish here to find the activities across the entire composition range with multiple phases.

The definition for the activity of a species $\mathrm{A}$ as a function of composition 


\begin{tabular}{|c|c|c|c|c|}
\hline T (K) & Transition & $\begin{array}{c}\log _{10} \sqrt{P} \text { Calculated } \\
\text { Without Phonons }\end{array}$ & $\begin{array}{c}\log _{10} \sqrt{P} \text { Calculated } \\
\text { With Phonons }\end{array}$ & $\log _{10} \sqrt{P}$ Experimental [42] \\
\hline 1000 & $\mathrm{PdS}_{\text {to } \mathrm{Pd}_{16} \mathrm{~S}_{7}}$ & -1.1 & -1.8 & $-2.2^{*}$ \\
\hline 1000 & $\mathrm{Pd}_{16} \mathrm{~S}_{7}$ to $\mathrm{Pd}_{4} \mathrm{~S}$ & -1.4 & -2.6 & $-2.4^{*}$ \\
\hline 1000 & $\mathrm{Pd}_{4} \mathrm{~S}$ to $\mathrm{Pd}$ & -3.3 & -5.3 & -5.2 \\
\hline 800 & $\mathrm{PdS}_{\mathrm{S}} \mathrm{Pd}_{16} \mathrm{~S}_{7}$ & -3.1 & -3.5 & -3.7 \\
\hline 800 & $\mathrm{Pd}_{16} \mathrm{~S}_{7}$ to $\mathrm{Pd}_{4} \mathrm{~S}$ & -3.5 & -4.5 & -4.7 \\
\hline 800 & $\mathrm{Pd}_{4} \mathrm{~S}$ to $\mathrm{Pd}$ & -5.9 & -7.6 & $* *$ \\
\hline
\end{tabular}

Table 4: Sulfidization threshold pressures for the $\mathrm{Pd}-\mathrm{S}_{2}$ system. Calculated values with and without phonon contributions are separately shown. Values * are liquid experimentally, but were extrapolated from the solid region of the predominance diagram for comparison purposes. ${ }^{* *}$ not indicated in experimental results.

$x_{A}$, pressure $\mathrm{P}$, and temperature $\mathrm{T}$ is $[43]$

$$
\log a_{A}\left(x_{A}, P, T\right)=\frac{\mu_{A}\left(x_{A}, P, T\right)-\mu_{A}^{0}(P, T)}{k_{B} T}
$$

where $a_{A}$ is the activity for species $\mathrm{A}, \mu_{A}\left(x_{A}\right)$ is the chemical potential for species $\mathrm{A}$, and $\mu_{A}^{0}$ is a reference chemical potential for species A. As we are specifying $x_{A}, \mathrm{P}$, and $\mathrm{T}$, the natural choice of thermodynamic potential is the Gibbs free energy,

$$
G=G\left(N_{A}, N_{B}, p, T\right)=\mu_{A} N_{A}+\mu_{B} N_{B},
$$

where $N_{A}$ and $N_{B}$ are the total number of $\mathrm{A}$ and $\mathrm{B}$ atoms, respectively, and the thermodynamic derivative giving the chemical potential is

$$
\mu_{A}\left(N_{A}, N_{B}, P, T\right)=\left.\frac{\partial G}{\partial N_{A}}\right|_{N_{B}, P, T} .
$$

However, the quantity of importance for phase transitions is the Gibbs free energy per atom,

$$
g=g\left(x_{A}, P, T\right)=\frac{G\left(N_{A}, N_{B}, P, T\right)}{N_{A}+N_{B}} .
$$

We may express the chemical potential in terms of intensive quantities as

$$
\mu_{A}\left(x_{A}, P, T\right)=g+\left.\left(1-x_{A}\right) \frac{\partial g}{\partial x_{A}}\right|_{P, T},
$$


where $x_{i}$ is the composition of species $\mathrm{i}$, and we have chosen to parameterize the free energy by the composition for A. Similarly,

$$
\mu_{B}\left(x_{A}, P, T\right)=g+\left.\left(1-x_{B}\right) \frac{\partial g}{\partial x_{B}}\right|_{P, T}=g-\left.x_{A} \frac{\partial g}{\partial x_{A}}\right|_{P, T} .
$$

These activities depend only on the free energy and the derivative of the free energy at a given composition. They are piecewise analytic functions across the composition range, completely determined by the thermodynamically stable phase at that composition. The activities can therefore be viewed as alternative representation of the underlying phase diagram for the system. They are discontinuous only when the derivative of the free energy changes (the free energy itself must always be continuous, due to the requirement of convexity).

As mentioned before, we believe the magnitude of the calculated free energy of our fcc phase is artificially large, destabilizing the $\beta$ phase, and thus any calculated activities would be flawed near the $50 \% \mathrm{Cu}$ region of the phase diagram. To support this assertion, here we refit the fcc phase using only low-solubility first principles data on either side of the composition range. This reduces the magnitude of the free energy of the fcc phase while still using first principles derived calculations. This should not be viewed as abandoning our pure first principles phase diagram as shown before, but rather a correction inspired by known experimental results presented in an alternative-but-equivalent format. The SQS estimate for fcc at 50\% Pd lies almost directly on this free energy curve, further supporting its usage for quantitative estimates. We also neglect phonon free energy for activity calculations, as for ordered fcc and bcc at $50 \%$ $\mathrm{Pd}$, the difference in phonon free energy per atom is only $2 \mathrm{meV}$ at $\mathrm{T}=1000 \mathrm{~K}$.

Shown below in Figure 9 in solid lines are our calculated activities for palladium in the $\mathrm{Cu}-\mathrm{Pd}$ binary, using the free energy models from Table 3 , the modified fcc phase, and our calculated data for $\mathrm{Cu}_{3} \mathrm{Pd}$. The $\beta$ phase is the sharply increasing region in the center of the graph. This sharp behavior is due to the entropic portion of the free energy, which has a logarithmic singularity at $\mathrm{x}=0.5$ and sharply varying derivative near this singularity. The smooth curves on the left and right sides of the graph for $\mathrm{T}<1000 \mathrm{~K}$ denote the fcc phase. Lin- 
ear free energy functions give constant activities as a function of composition, and thus phase coexistence regimes appear as plateaus in activities, at a fixed temperature. Two sets of plateaus are present. The set of plateaus on the left side are coexistence regimes between the bcc and fcc phases. There are 3 types of plateaus on the right side. For $\mathrm{T}<900 \mathrm{~K}$, the plateaus are due to coexistence with the line compound $\mathrm{Cu}_{3} \mathrm{Pd}$, where the plateaus in the region $0.6<x<0.8$ indicate coexistence with bcc and the plateaus at $0.8<x<0.9$ indicate coexistence with fcc. The plateau on the right side of the plot for $\mathrm{T}=900 \mathrm{~K}$ is a special case. Our free energy models predict that the $\mathrm{Cu}_{3} \mathrm{Pd}$ phase becomes thermodynamically unstable at $899 \mathrm{~K}$ and fcc becomes stable, so the plateau at $900 \mathrm{~K}$ indicates coexistence between bcc and fcc. At a temperature of 960K, our model predicts that the bcc phase becomes unstable relative to the fcc phase, disappearing at a composition of $\mathrm{x}=0.576$. By decreasing the fcc free energy magnitude we have properly stabilized the $\beta$ phase at temperatures of interest and brought the transition temperature to within $90 \mathrm{~K}$ of the expected value. The $1000 \mathrm{~K}$ and $1350 \mathrm{~K}$ plots are pure fcc throughout the entire composition range.

The activities of $\mathrm{Pd}$ at various temperatures were also calculated using CALPHAD (acronym of CALculation of PHAse Diagrams) method. The thermodynamic database developed by Li et al[8] was used. Our activities are systematically low compared to the CALPHAD activities (shown in dashed lines on Figure 9], most likely due to our ideal entropy approximation. As the true entropy in solid solutions is reduced relative to the ideal entropy, the true free energy will be greater, leading to the true activities being greater than our calculated activities. This is especially true for fcc, where the refitted free energy still overestimates the magnitude of the free energy and leads to qualitatively different behavior in the high $\mathrm{Pd}$ limit. CALPHAD results give activities that exceed Raoult's Law in the high $\mathrm{Pd}$ limit, which would require positive enthalpies of formation for $\mathrm{Cu}$ substitution in Pd using a solid substitution model in the dilute limit. This contradicts first principle calculations which unambiguously predict $\mathrm{Cu}$ substitutions in bulk Pd having negative enthalpies of formation (see Figure 


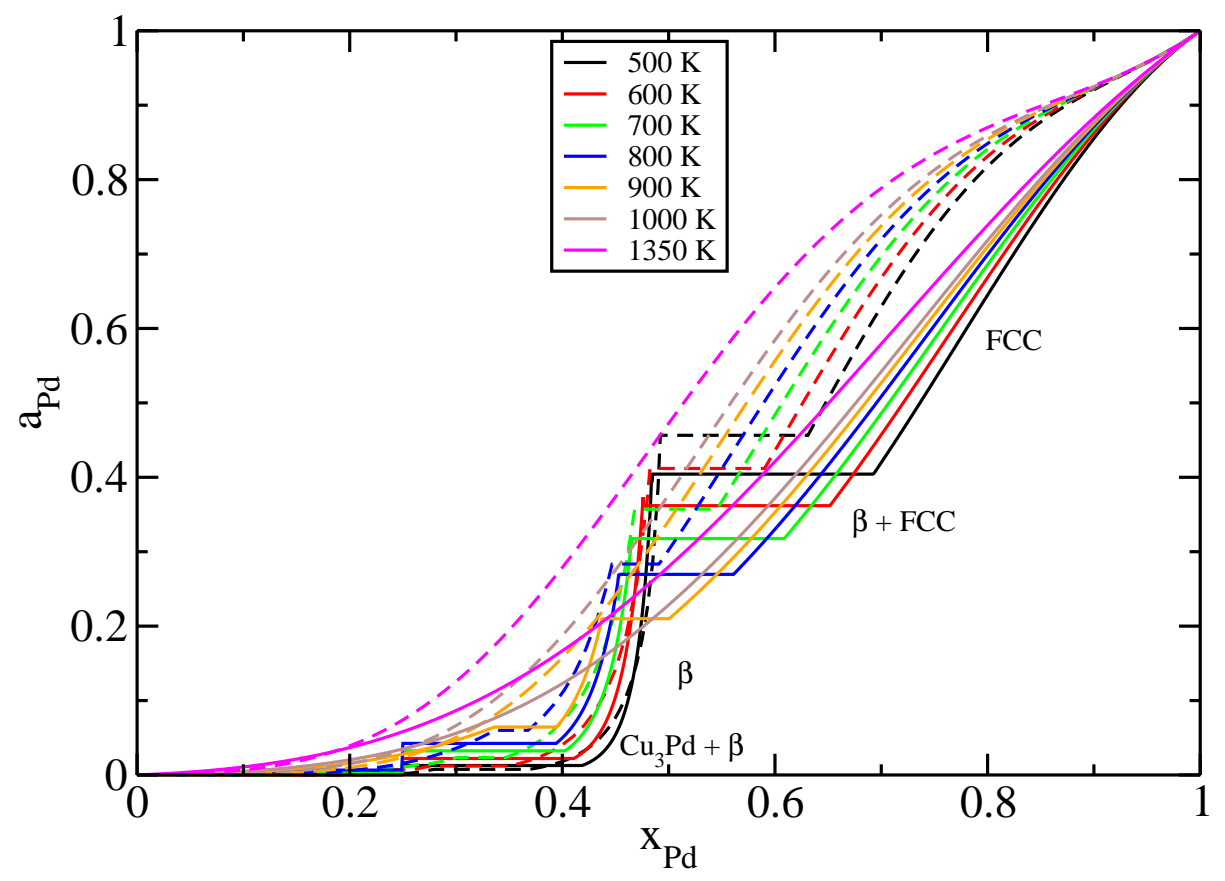

Figure 9: (color online) Activities of $\mathrm{Pd}$ in the $\mathrm{Cu}-\mathrm{Pd}$ binary. First principles results are denoted with solid lines, and CALPHAD with dashed lines.

11). Clearly more precise models are needed to understand the binary in the high $\mathrm{Pd}$ limit. However, for the $\beta$ phase and associated coexistence regimes, the first principles and CALPHAD results are in close agreement, and if one is interested in regions outside the single-phase fcc region, first principles calculations gives reasonably accurate results even with simple models.

\section{Conclusions}

Using only first principles calculations and solid solution models, we were able to semi-quantitatively model the ternary phase diagram for the $\mathrm{Cu}-\mathrm{Pd}$-S system without any empirical fitting parameters. We obtained the sulfidization thresholds for the $\mathrm{Pd}-\mathrm{S}_{2}$ system and activities that reflect the essential features of the $\mathrm{Cu}-\mathrm{Pd}$ binary system at temperatures where multiple phases exist across the composition range. More detailed models are necessary to reach better 
quantitative agreement with experimental results. However, our work reveals the essential physics underlying the phase behavior. For example, we distinguish enthalpic vs. entropic driven substitution, and we identify a pseudogap stabilization mechanism, yielding a temperature-independent solubility range for $\mathrm{Cu}$ in $\mathrm{Pd}_{16} \mathrm{~S}_{7}$.

\section{Acknowledgements}

We are grateful to B. Gleeson, M. Mihalkovič, and J. Kitchin for useful discussion. This technical effort was performed in support of the Fuels Program of Strategic Center for Coal at DOE National Energy Technology Laboratory under the RES contract de-fe0004000.

\section{References}

[1] C.-H. Chen, Y. H. Ma, J. Membr. Sci 362 (2010) 535-544.

[2] H. Amandusson, L.-G. Ekedahl, H. Dannetun, J. Membr. Sci 193 (2001) $35-47$.

[3] S. Uemiya, T. Matsuda, E. Kikuchi, J. Membr. Sci 56 (1991) 315-325.

[4] O. Iyoha, R. Enick, R. Killmeyer, B. Morreale, J. Membr. Sci. 305 (2007) $77-92$.

[5] C. P. O'Brien, B. H. Howard, J. B. Miller, B. D. Morreale, A. J. Gellman, J. Membr. Sci. 349 (2010) 380-384.

[6] S. Karup-Møller, E. Makovicky, N. Jb. Miner. Mh. 12 (1999) 551-567.

[7] P. R. Subramanian, D. E. Laughlin, J. Phase Equilib. 12 (1991) 231-243.

[8] M. Li, Z. Du, C. Guo, C. Li, CALPHAD 32 (2008) 439-446.

[9] G. Trimarchi, A. Zunger, J. Phys.-Condens. Mat. 20 (2008) 295212.

[10] S. Baärthlein, E. Winning, G. L. W. Hart, S. Müller, Acta Mater. 57 (2009) $1660-1665$. 
[11] G. Ceder, D. de Fontaine, H. Dreysse, D. M. Nicholson, G. M. Stocks, B. L. Gyorffy, Acta Metall. Mater. 38 (1990) 2299-2308.

[12] B. J. Lee, B. Sundman, S. I. Kim, K. G. Chin, ISIJ Int. 47 (2007) 163-171.

[13] H. Okamoto, J. Phase Equilib 13 (1992) 106-107.

[14] G. Kresse, J. Hafner, Phys. Rev. B 43 (1993) 558-561.

[15] G. Kresse, J. Furthmüller, Phys. Rev. B 54 (1996) 11169-11186.

[16] P. E. Blöchl, Phys. Rev. B 50 (1994) 17953-17979.

[17] R. Hu, M. C. Gao, O. N. Doğan, P. King, M. Widom, CALPHAD 34 (2010) 324-331.

[18] J. P. Perdew, A. Ruzsinszky, G. I. Csonka, O. A. Vydrov, G. E. Scuseria, L. A. Constantin, X. Zhou, K. Burke, Phys. Rev. Lett. (2008).

[19] E. J. Wu, G. Ceder, A. van de Walle, Phys. Rev. B 67 (2003) 134103.

[20] E. A. Owen, E. L. Yates, Philos. Mag 15 (1933) 472-487.

[21] I. R. Harris, M. Norman, W. E. Gardner, J. Less-Common Metals 29 (1972) 299-309.

[22] K. Okamura, J. Phys. Soc. Jpn 28 (1970) 1005-1014.

[23] H. T. E. Jr., Science 203 (1979) 356-358.

[24] M. Leon, N. Terao, F. Rueda, Phys. Status Solidi A 67 (1981) K11-K14.

[25] H. Fjellvåg, F. Grnvold, S. Stlen, A. F. Andresen, R. Müller-Käfer, A. Simon, Z. Krist. 184 (1988) 111-121.

[26] H. E. King, C. T. Prewitt, Am. Mineral. 64 (1979) 1265-1271.

[27] F. Grønvold, E. Røst, Acta Cryst. 15 (1962) 11-13.

[28] P. Matkovič, M. El-Boragy, K. Schubert, J. Less-Common Met. 50 (1976) $165-176$. 
[29] T. F. Gaskell, Z. Kristallogr. 96 (1937) 203-213.

[30] F. Grønvold, E. Røst, Acta Cryst. 10 (1957) 329-331.

[31] A. Janosi, Acta Cryst. 17 (1964) 311-312.

[32] M. Guymont, D. Gratias, Phys. Status Solidi A 36 (1976) 329-334.

[33] E. Røst, Acta Chem. Scand. 22 (1968) 819-826.

[34] A. Soutter, A. Colson, J. Hertz, Mem. Etud. Sci. Rev. Metall. 68 (1971) $575-591$.

[35] A. H. Geisler, J. B. Newkirk, J. Met. 6 (1954) 1076-1082.

[36] K. Yamamoto, S. Kashida, J. Solid State Chem. 93 (1991) 202-211.

[37] D. Topa, E. Makovicky, T. Balić-Žunić, Can. Mineral. 44 (2006) 497-505.

[38] E. Bruno, B. Ginatempo, E. S. Giuliano, Phys. Rev. B 63 (2001) 174107.

[39] C. Wolverton, Acta Mater. 49 (2001) 3129-3142.

[40] J. Friedel, Helv. Phys. Acta 61 (1988) 538-555.

[41] J. M. W. Chase, J. Phys. Chem. Ref. Data 9 (1998) 1-1951.

[42] J. R. Taylor, Met. Trans. B 16B (1985) 143-148.

[43] R. DeHoff, Thermodynamics in Materials Science, 2nd ed., CRC Press, 2006. 